\title{
Comparison of growth curves of three strains of female dairy cattle
}

\author{
D. P. Berry†, B. Horan and P. Dillon \\ Dairy Production Department, Teagasc, Moorepark Production Research Centre, Fermoy, Co. Cork, Ireland \\ †E-mail : dberry@moorepark. teagasc. ie
}

\begin{abstract}
The objective of the present study was to compare growth curves for live weight (LW) and body size of three strains of female dairy cattle reared under common environments in Ireland. One strain (HP) was selected from a predominantly North-American/European Holstein-Friesian genetic pool selected for high milk production. The second strain (HD) represented a predominantly North-American/European Holstein-Friesian genetic pool selected for high milk production but with greater selection emphasis on functional non-production traits. The third strain (NZ) consisted of New Zealand Holstein-Friesian females of high genetic merit for profitability in New Zealand. The data consisted of 99 animals (33 animals in each strain) with records on LW, length, girth and height from birth to a minimum of 594 days of age. The von Bertalanffy growth function was fitted to each animal's records separately and least-squares analyses were used to investigate the effect of strain on birth LW/body size, parameters of the growth function and average daily gains. Average mature live weight of the HD animals (591 kg) was significantly larger than that of the HP (566 kg) or NZ (543 kg) strain; the $H D$ strain matured more slowly. The HD $(134 \mathrm{~cm})$ and $H P(135 \mathrm{~cm})$ strains were significantly taller than the NZ (128 cm) strain. Although the data set was relatively small there are indications that dairy females of North-American genetic origin were heavier at birth, grew faster, and were heavier and taller at maturity than dairy females of New Zealand origin.
\end{abstract}

Keywords: dairy cattle, growth curve, strain differences.

\section{Introduction}

Previous studies have shown that live weight (LW) in dairy cattle has a negative economic value in terms of profitability since the marginal cost associated with the increased energy demands of rearing heifers and the higher maintenance requirements of heifers and cows exceed the marginal revenue of heavier cull cow carcasses (Groen, 1989; Visscher et al., 1994). The New Zealand dairy industry has included LW, with a negative economic value, in their national breeding objective since 1988 (Ahlborn-Breier and Wickham, 1990); in 2004, 19\% of the relative emphasis in the breeding objective was on LW. Because farm size is typically the limiting factor in New Zealand, dairy farmers have traditionally sought cows that are efficient converters of food to milk; this generally implied relatively small cows capable of producing moderate to high volume of milk solids. The United States dairy industry introduced a body size composite, with a negative weighting, in their selection objective in 2000 (Van Raden and Seykora, 2004); however, since its inclusion in the breeding objective the relative emphasis on body size has remained below $5 \%$. Therefore, LW of New Zealand bred animals is expected to be lower than animals with a higher proportion of North-American genetics. Because of the strong association between LW and body size (Heinrichs et al., 1992) New Zealand animals may also be expected to be smaller animals. The effect of genetic origin on LW and body size, under Irish conditions, may be tested by measuring LW and body size at different ages across different strains commonly reared and producing under the same environments.

However, a series of LW/body size records at different ages is analytically unwieldy and difficult to interpret. Non-linear algebraic models are an effective method of describing individual growth patterns in a small number of biologically interpretable parameters. Such models tend to reduce the effect of temporary environment/random variation as well as adjusting for the non-linear relationship between age and LW/body size. Non-linear functions previously used to describe sigmoidal LW growth patterns in dairy and beef cattle are the Brody (Brody, 1945), Gompertz (Winsor, 1932), logistic (Pearl and Reed, 1923), von Bertalanffy (von Bertalanffy, 1957), and Richards growth functions (Richards, 1959). Previous studies evaluated the appropriateness of the alternative growth functions across different data sets of LW-age data points (Bakker and Koops, 1978; Brown et al., 1976; Koenen and Groen, 1996; Perotto et al., 1992). However, there was no general consensus of the most universally suitable growth function except that the selected function should depend upon the nature of the study and the intended application of the results.

Average LW of Holstein-Friesian cows, 6 years of age and older, participating in the Sire Proving Scheme in New Zealand during 2002/2003 varied from $530 \mathrm{~kg}$ to $539 \mathrm{~kg}$ (Livestock Improvement Corporation, 2003). Hoffman 


\section{Berry, Horan and Dillon}

(1997) reviewed seven studies from the US and Canada on primiparous Holstein cows between 1977 and 1996; mean LW in the 1st week post calving was 559 (s. d. = 39) kg. Koenen and Groen (1996) estimated a mature LW of 546 to $667 \mathrm{~kg}$ in Dutch black and white cows. Harris and Winkelman (2000) estimated a difference in breed effects of $44.4 \mathrm{~kg}$ LW between North-American Holstein-Friesian and New Zealand Holstein-Friesian cows participating in the Sire Proving Scheme in New Zealand between 1987 and 1999. Nevertheless, differences in LW observed between counties may be attributable to differences in managerial practices among countries while differences between strains within countries may be an artifact of preferential treatment of certain animals. No recent study has attempted to describe possible differences in growth related parameters between New Zealand and North American Holstein-Friesians commonly reared and producing under similar pasturebased environments.

Differences in mature LW may also influence growth patterns among alternative strains. Koenen and Groen (1996) reported heritability estimates ranging from 0.02 to 0.31 for the various parameters of growth functions derived from data on black and white dairy heifers. Thus, differences in growth parameters (e.g. average daily LW gain) may also differ between strains.

Gallo et al. (2001) reported a mean heart girth of $201 \mathrm{~cm}$ in Italian primiparous Holstein-Friesian cows. Sieber et al. (1988) reported a mean heart girth circumference of 187.5 $\mathrm{cm}$ across 765 primiparous Holstein-Friesian cows in the first 35 to 50 days post partum; the corresponding wither height of these animals was $131.2 \mathrm{~cm}$. Cue et al. (1996), using linear type classification data in New Zealand, reported a vertical height to the shoulders of around 125 to $130 \mathrm{~cm}$ in primiparous cows sired by Holstein-Friesians. Recommended wither height at first calving in the United States is between $138 \mathrm{~cm}$ and $141 \mathrm{~cm}$ (Hoffman, 1997). Reported differences in body size among international studies also suggest possible strain effects on body size.

The objective of the present study was to compare descriptive growth statistics for LW and body size of different strains of female dairy cattle of North American/European origin or New Zealand origin.

\section{Material and methods}

Live weight, body condition score (BCS) and body size data were collected from January 1998 to December 2003 on 99 animals at Moorepark Research Centre in Southern Ireland. All 99 animals were born between 27 December 1998 and 1 May 1999 and calved for their first time between 13 January 2001 and 17 March 2003; age at first calving varied from 655 days to 822 days.

\section{Strains}

Three strains of Holstein-Friesian cows were compared: high production North American (HP), high durability North American (HD) and New Zealand (NZ). Each strain comprised 33 animals each. Development of the strains is described in more detail by Horan et al. (2004). The HP strain was created to represent animals of high genetic merit for milk production. This was achieved by selecting both sires and dams of superior genetic merit for milk production. The top $50 \%$ of cows in the Moorepark Research herd (based on pedigree index for milk production) were inseminated with semen from five North American sires to generate the HP strain; cows in the Moorepark Research herds are somewhat genetically superior for milk production compared with the average Irish cow. The five sires were chosen on the basis of their superior pedigree index for milk production. The mean predicted transmitting abilities (PTAs) for the five sires were +306 (s. d. $=56.2$ ) kg milk, +11.9 (s. d. $=2.77$ ) kg fat, +12.8 (s. d. $=2.59$ ) $\mathrm{kg}$ protein, +0.00 (s. d. $=0.069$ ) $\mathrm{g}$ fat per kg milk, 0.05 (s. d. $=0.043$ ) g protein per kg milk, -0.88 (s. d. $=1.10$ ) percent survival and +1.08 (s. d. $=2.46$ ) days calving interval. The average proportion of Holstein-Friesian genes in the HP strain was $90 \%$.

Based on pedigree index for milk production, the bottom $50 \%$ of cows in the Moorepark Research herd were inseminated with semen from five North American sires to generate the HD strain. The five sires were chosen on the basis of their superior milk production, fertility and linear (muscularity, body condition score) traits. The PTAs for the five sires were +110 (s. d. = 128.3) kg milk, $+9 \cdot 3$ (s. d. = 4.9) $\mathrm{kg}$ fat, $+8 \cdot 1$ (s. d. $=2.2$ ) $\mathrm{kg}$ protein, $+0 \cdot 10$ (s. d. $=0.13$ ) g fat per kg milk, +0.09 (s. d. $=0.07$ ) g protein per kg milk, -0.08 (s. d. $=1 \cdot 16) \%$ survival and -1.5 (s. d. $=1.87$ ) days calving interval. Average sire PTA for body condition score was $+1 \cdot 41$ units and +0.06 for the HD and HP strain, respectively. The average proportion of Holstein-Friesian genes in the HD strain was $80 \%$.

The NZ strain animals were imported as embryos from New Zealand and implanted into Holstein-Friesian animals in Moorepark Research Centre. They were selected using dams of superior genetic merit as expressed in the New Zealand genetic evaluation system (Breeding Worth) mated to five proven New Zealand sires of better than average genetic merit for Breeding Worth. On average, $87.5 \%$ of the NZ strain genes were of New Zealand Holstein-Friesian ancestry. Jersey genes contributed up to a maximum of $12.5 \%$, with the remaining genes of North American Holstein-Friesian ancestry. The mean PTAs for the five sires were +65 (s. d. $=9 \cdot 2$ ) kg milk, $+13 \cdot 4$ (s. d. = 4.6) kg fat, $+6 \cdot 1$ (s. d. = 1.0) $\mathrm{kg}$ protein, +0.21 (s. d. $=0.089$ ) $\mathrm{g}$ fat per $\mathrm{kg} \mathrm{milk,}+0.08$ (s. d. $=0.017$ ) g protein per kg milk,+1.22 (s. d. $=1.09$ ) $\%$ survival and $-2 \cdot 1$ (s. d. $=0 \cdot 82$ ) days calving interval.

\section{Measurements}

Virgin heifers were weighed weekly from birth using an electronic scale. Virgin heifers were also assessed monthly for body size based on three objective measurements. Length of the animal was recorded as the horizontal distance from the top of the withers to the ischium. Girth was defined as the circumference of the animal's barrel measured immediately behind the front legs. Height of the animal was recorded as the vertical distance from the top of the withers to the ground. All measures were recorded in centimetres.

Post first calving, cows continued to be weighed weekly up to the end of their third lactation. Measurements of body size 


\section{Growth curves for three strains of cattle}

were recorded twice in first and second lactation and once in third lactation. During the first three lactations animals were also assessed every 3rd week for BCS on a scale of 1 to 5 (Lowman et al., 1976); the same classifier assessed all animals throughout the study.

The number of LW records per animal included in the analysis varied from 127 to 230 . The age of last LW record varied from 948 days to 1834 days; the average interval between LW records across all animals was 8 days. The number of records for body size varied from 15 to 27 . The age of last body size record varied from 594 to 1683 days of age; the average interval between body size records across all animals was 65 days.

\section{Heifer rearing and feeding systems}

Calves were reared in accordance with procedures outlined by Fallon and Harte (1987). All newborn heifer calves were penned individually and fed colostrum for the first 3 days of life. Thereafter, they were fed 2 I of whole milk daily up to 3 weeks of age. Calves were subsequently grouped in pens of up to 15 calves per pen and offered ad libitium whole milk and ad libitium hay up to 8 weeks of age. Calf concentrates were offered up to a maximum of $2 \mathrm{~kg}$ per head daily or a total allowance of $100 \mathrm{~kg}$ per calf. All calves were weaned at 8 weeks of age. Weather permitting, calves were turned out to grass as soon as possible post weaning and grazed ahead of yearling heifers in a leader/follower rotational grazing system. Animals were re-housed in December and were provided access to ad libitium silage and $1 \mathrm{~kg}$ concentrates daily. Animals were turned out to pasture the following February and returned indoors the following November. Throughout their life all animals were treated for the control of internal and external parasites. The heiferrearing programme was designed to maximize growth off grazed grass without over-conditioning the heifers.

Post first calving, all animals within a strain were randomly assigned to one of three feeding systems on the basis of calving date and pre-experimental milk yield; animals remained in their allocated feeding system for the rest of the study. The three feeding systems compared were : the Moorepark system, with high milk output from pasture, a high concentrate feeding system and a high stocking rate feeding system. All three feeding systems are described in more detail by Horan et al. (2004).

\section{Growth parameter estimation}

Prior to inclusion in the analyses, post calving LW records of cows on the high concentrate and high stocking rate feeding systems were adjusted to LW equivalents on the Moorepark feeding system. The Moorepark feeding system represents the optimal feeding system under Irish spring calving production systems and reflects the production environments in most spring calving herds in southern Ireland. Adjustment for feeding system was achieved using PROC GLM (Statistical Analysis Systems Institute (SAS), 2004) for each parity separately to account for feeding system by parity interactions. The dependent variable was LW and the independent variables included a main effect for feeding system and a two-way interaction between feeding system and a cubic regression on age. The adjusted records (including the unadjusted records of the cows on the Moorepark feeding system) were appended to the records of the virgin heifers.

Preliminary analysis of the body size data revealed no significant effect of feeding system on either length, girth or height; these data were therefore not adjusted for feeding system but appended directly to the body size records of the virgin heifers.

Although the objective of this study was not to evaluate the optimal growth function to fit these data, preliminary analyses were performed by fitting several growth functions across all LW data for each animal separately. The alternative growth functions investigated were the Brody (Brody, 1945), Gompertz (Winsor, 1932), logistic (Pearl and Reed, 1923), von Bertalanffy (von Bertalanffy, 1957), and Richards growth functions (Richards, 1959). All growth functions were fitted using PROC NLIN (SAS, 2004) with alternative iterative methods and alternative parameter starting values. The maximum number of iterations to reach convergence for each growth function was set to 10000 . Convergence was achieved when

$$
\left(S S E_{i-1}-S S E_{i}\right) /\left(S S E_{i}+10^{-6}\right)<10^{-8}
$$

where $S S E$ is the residual sum of squares and $i$ denotes the round of iteration.

Only the von Bertalanffy and Brody functions converged for all animals using all iterative methods. However, birth weight predicted with the Brody growth function was negative for 76 out of the 99 animals; birth weight predicted using the von Bertalanffy growth function was positive for all animals. Therefore, the von Bertalanffy function, using the modified Gauss-Newton iterative method, was fitted to all LW data and is the only growth function described herein. The von Bertalanffy function was also fitted to all body size measurements. The von Bertalanffy function is described as:

$$
Y_{t}=A\left(1-B e^{-k \cdot t}\right)^{3}
$$

where : $Y_{t}=$ dependent variable (LW/length/girth/height) at age $t$ (in days); $A=$ asymptotic mature LW/length/girth/height (in $\mathrm{kg}$ or $\mathrm{cm}$ ); $B=$ constant of integration; $k=$ maturing rate (per day).

The asymptotic limit $(A)$ of each animal as age $(t)$ approaches infinity does not approximate the largest LW/length/girth/ height attained by an animal; it is the asymptotic mean LW/ length/girth/height. The constant of integration $(B)$ adjusts for situations where $Y_{0}$ and/or $t_{0}$ do not equal zero; it has no biological interpretation.

Rate of maturing $(k)$ refers to the post-natal growth rate relative to the mature variable (i.e. LW/length/girth/height). It expresses the rate with which the logarithmic function of the dependent variable $(Y)$ changes linearly with time. For example, when two animals are growing to a similar mature LW, differences in maturation rate reflect differences in absolute growth. Large $k$ values indicate early maturing animals and small $k$ values indicate late maturing animals.

The first derivative of $Y$ with respect to time $(d Y / d t)$ is a measure of absolute growth rate. The first derivative in 


\section{Berry, Horan and Dillon}

this study represents an instantaneous measure of daily gain. Average daily gain within a given time interval is approximated by $d Y / d t$ at the mid point of the time interval and may be calculated for any time interval based on the results reported in this study. The first derivative was used to calculate average daily LW gain throughout life. The first derivative of the von Bertalanffy is

$$
\frac{d Y}{d t}=3 A k B e^{-k_{-} t}\left(1-B e^{-k_{-} t}\right)^{2}
$$

Maximum average daily gain was estimated per animal by constraining the second derivative of the von Bertalanffy function to zero and solving for age.

\section{Goodness of fit}

Usual goodness of fit statistics may be inaccurate if correlated errors exist among the longitudinal data points (Grizzle and Allen, 1969). The presence of auto-correlations among residuals were therefore tested using the DurbinWatson statistic (Durbin and Watson, 1951) in PROC REG (SAS, 2004). Residuals were calculated as the difference between actual LW/body size and predicted LW/body size at each age. The mean square prediction error was calculated as the average variance of the daily residuals per animal. The proportion of variation accounted for $\left(R^{2}\right)$ was calculated as [1-residual mean square]/[variance of dependent variable]. The coefficient of variation of the residuals was also calculated at birth, 100 and 600 days of age as the square root of the residual mean square error divided by the observed average of LW/body size records; this term will also provide an indication of the fit of the growth function to the data.

\section{Analysis}

A least-squares analysis was performed to investigate the effect of strain on each of the three coefficients of the von Bertalanffy growth function for LW, length, girth, and height using PROC GLM (SAS, 2004). The independent factors included in the model were strain (HP, HD and NZ) and month of birth (January, February, March, April). One animal was born at the end of December and one animal was born at the start of May; these animals were placed in the level corresponding to January and April, respectively. Age at calving was included as a linear covariate; higher polynomials did not significantly $(P>0.05)$ affect any of the dependent variables investigated. Age of the dam at calving did not significantly $(P>0.05)$ affect any of the traits under investigation and was therefore not included in the model; age of dam varied from 661 days to 1451 days.

Least-squares means for strain were extrapolated from the analyses and the difference between strains was tested using a two-sided $t$ test with the appropriate degrees of freedom. Similar analyses were also performed on other variables of interest, such as birth LW/body size, calving LW/body size and average daily gain in LW/body size at 100 and 600 days of age. Live weight/body size at calving was calculated using the von Bertalanffy parameters estimated per cow and the actual age of calving for each cow. Day 100 was chosen to represent growth in early life and day 600 was chosen since the effect of gestation is expected to be minimal at this age (Silvey and Haydock, 1978).

\section{Results}

Live weight

The residuals of predicting actual LW with the von Bertalanffy growth function fitted a normal distribution; the range of residuals varied from $-146 \mathrm{~kg}$ to $171 \mathrm{~kg}$. Residuals at birth, 100 and 600 days of age are summarized in Table 1. The coefficient of variation of the residuals at birth, 100, and 600 days of age was $0.27,0.08$ and 0.04 , respectively (Table 1). The correlation between the residuals and age was -0.02 and was significantly $(P<0.01)$ different from zero. The Durbin-Watson test revealed a significantly $(P<0.05)$ positive autocorrelation for all cows; the Durbin-Watson statistic across all residuals was $0 \cdot 2$. In general, the von Bertalanffy function tended to underestimate LW to around 175 days of age and overestimate LW to around 500 days of age. The residuals thereafter followed a cyclic pattern, underestimating LW during mid to late gestation and overestimating LW in early to mid lactation. The average mean square prediction error across all animals was $1231 \mathrm{~kg}^{2}$. The average $R^{2}$ across all animals was 0.95 (range of 0.91 to 0.99 ).

Because of the large residuals in estimating birth LW from the von Bertalanffy function concurrent with the large coefficient of variation of the residuals, a separate analysis was carried out on the effect of strain on actual birth LW as recorded by farm staff using a weighing scale; 82 animals had a record for LW at birth. The average birth LW for the HP, HD and NZ strains was 42 (s.e.1·1) kg, 43 (s.e.1.0) kg and 36 (s.e.1·1) kg.

Table 1 Actual and predicted values and coefficient of variation of residuals (CV) for live weight (kg) and length, girth and height measurements (cm) at birth, 100 and 600 days of age

\begin{tabular}{|c|c|c|c|c|c|c|c|c|c|}
\hline & \multicolumn{3}{|c|}{ Birth } & \multicolumn{3}{|c|}{100 days } & \multicolumn{3}{|c|}{600 days } \\
\hline & Actual & Predicted & CV & Actual & Predicted & CV & Actual & Predicted & CV \\
\hline Live weight & $40 \cdot 7$ & $31 \cdot 7$ & $0 \cdot 271$ & $108 \cdot 3$ & $100 \cdot 3$ & 0.082 & $477 \cdot 5$ & $448 \cdot 5$ & 0.041 \\
\hline Length & $66 \cdot 3$ & $71 \cdot 1$ & 0.053 & $77 \cdot 6$ & $77 \cdot 5$ & 0.056 & $112 \cdot 6$ & 113.5 & 0.036 \\
\hline Girth & $84 \cdot 1$ & $84 \cdot 7$ & 0.037 & $107 \cdot 6$ & $107 \cdot 8$ & 0.027 & $179 \cdot 2$ & 181 & 0.015 \\
\hline Height & $70 \cdot 4$ & $66 \cdot 8$ & 0.058 & $87 \cdot 7$ & $89 \cdot 3$ & 0.028 & $126 \cdot 4$ & $126 \cdot 5$ & 0.010 \\
\hline
\end{tabular}




\section{Growth curves for three strains of cattle}

Table 2 Least-squares means and standard errors (in parenthesis) for asymptotic live weight (A), constant of integration (B), maturation rate (k), maximum rate of average daily live-weight gain (ADG), age at maximum daily live-weight gain, and daily live-weight gain at day 100 and 600 for the high durability (HD), high production (HP), and New Zealand (NZ) strains

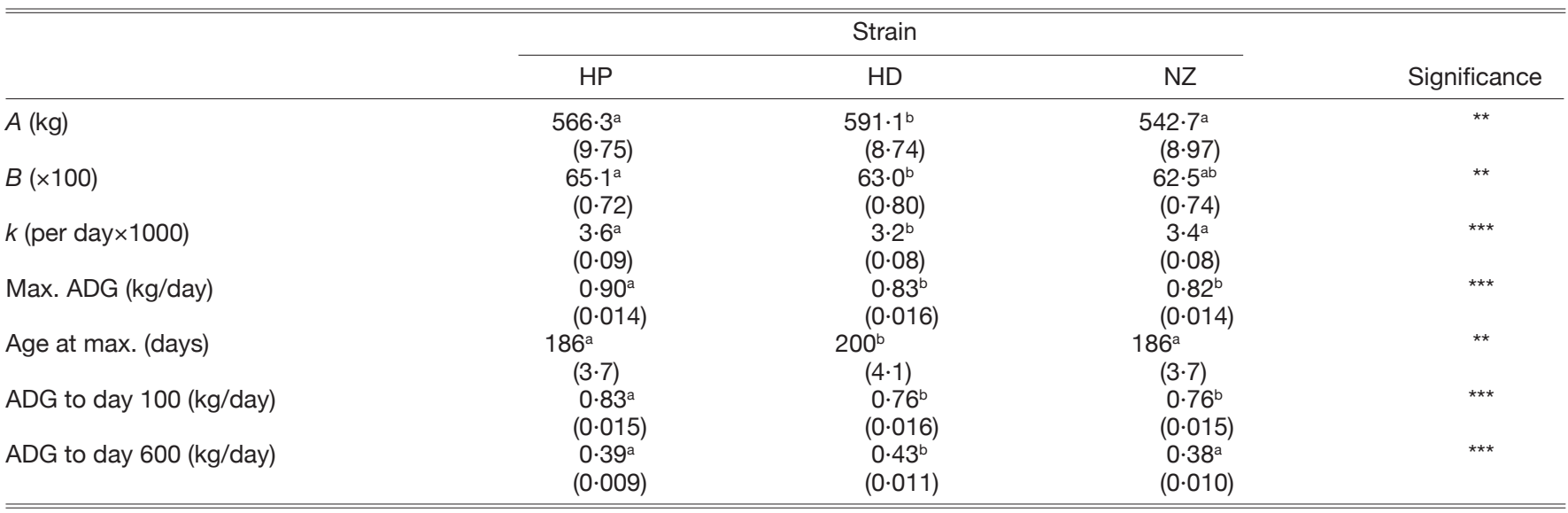

${ }^{\text {ab }}$ Means with different superscripts within the same row are significantly different $(P<0 \cdot 05)$.

The $A, B$ and $k$ parameters of the von Bertalanffy growth function for the three strains are summarized in Table 2. The growth curves estimated using the least-squares means of the von Bertalanffy growth function parameters across the three strains are shown in Figure 1. Average mature LW of the HD strain was significantly higher than average mature LW of either the HP or the NZ strains; differences in mature LW between the HP and NZ strains were not significant. However, following adjustment of LW to a common BCS of three, the HD strain had a significantly heavier mature LW than the HP which in turn had a significantly heavier mature LW than the NZ strain (results not shown).

Average daily LW gain for the three strains is graphically illustrated in Figure 2. Daily LW gain was greater in the HP strain relative to the other strains up to 408 days of age.
Daily LW gain of the HD and NZ strains was similar to around 175 days of age after which the HD strain had a greater LW gain than the NZ strain. Maximum daily LW gain, age at maximum daily LW gain, and LW gain at day 100 and 600 are summarized in Table 2. Maximum daily gain of the HP strain was significantly higher than that of the HD and the NZ strain. Maximum daily gain occurred at a significantly older age in the HD strain than in either the HP or NZ strains.

Average LW at first calving, estimated using the von Bertalanffy growth function (i.e. excluding the effect of foetus and associated foetal membranes and fluids) was 485 (s.e.5.7) kg, 481 (s.e.6.2) kg and 457 (s.e.5.7) kg for the HP, $\mathrm{HD}$ and NZ strains, respectively. Hence, LW at first calving represented proportionately $0.86,0.81$ and 0.84 of mature LW in the HP, HD and NZ strains, respectively.

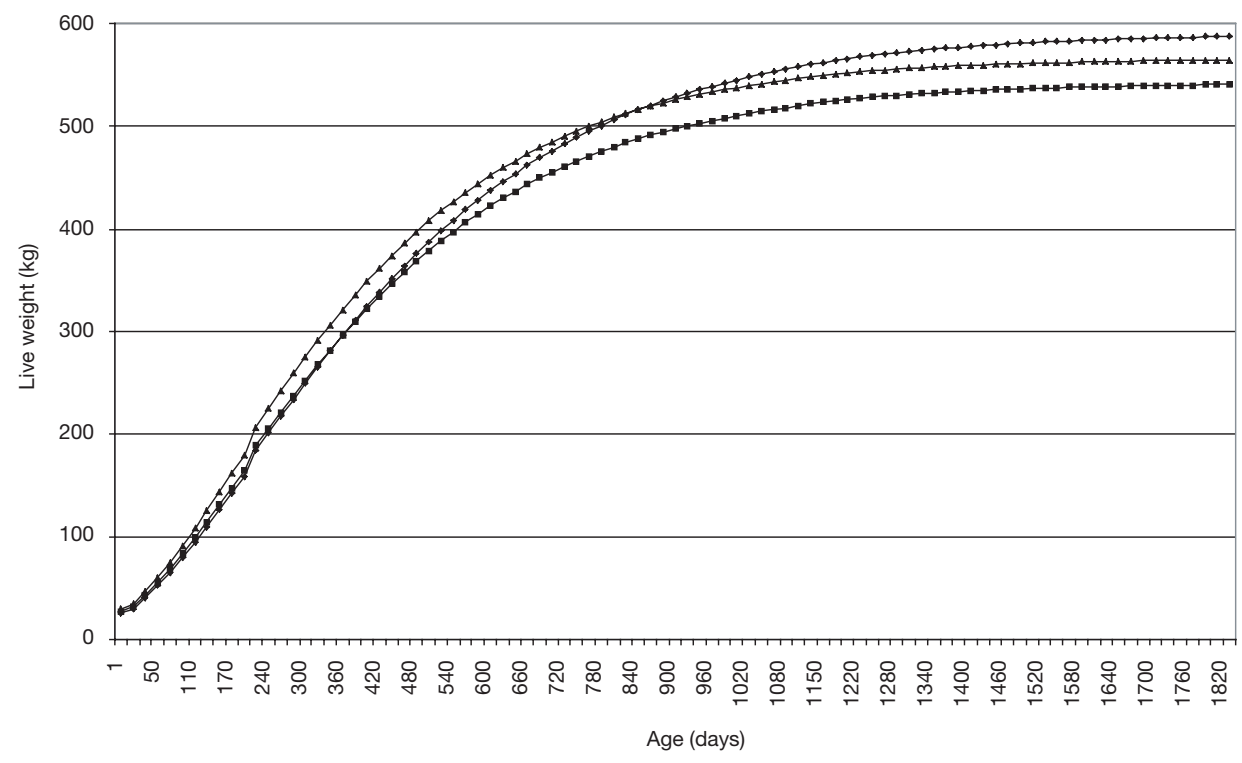

Figure 1 Live weight profiles of the high durability $(\diamond)$, high production $(\mathbf{\Delta})$, and New Zealand $(\boldsymbol{\square})$ strains estimated using the von Bertalanffy growth function. 
Berry, Horan and Dillon

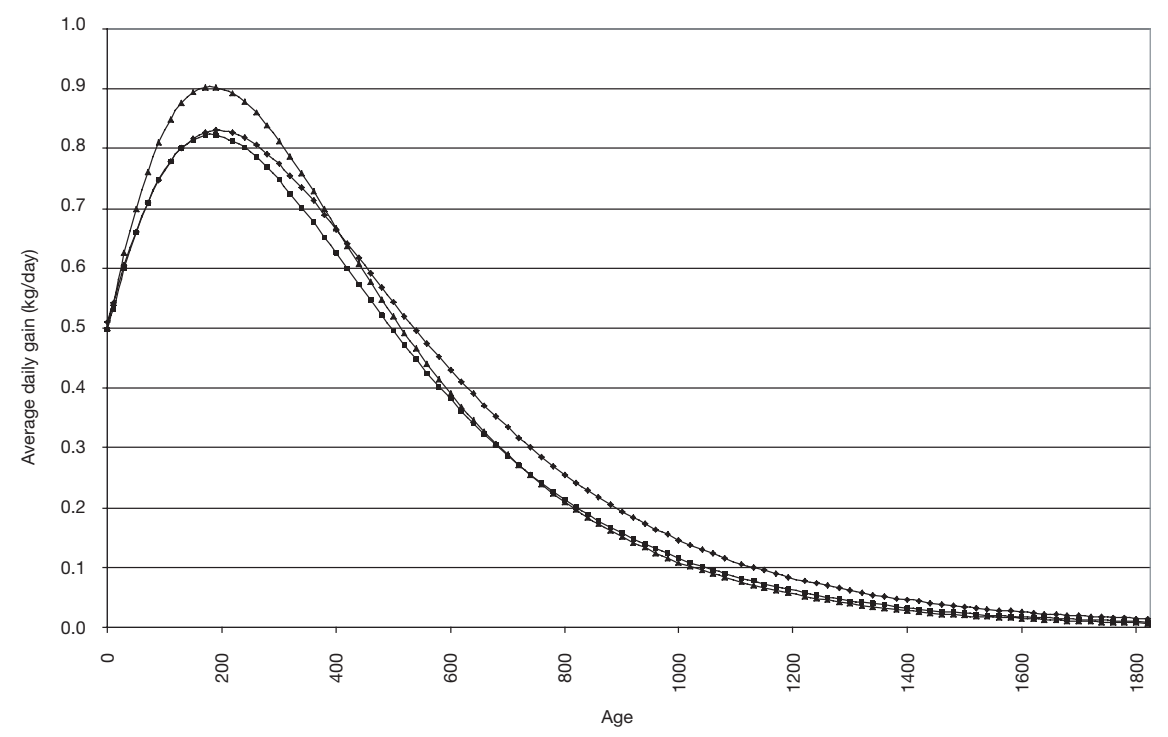

Figure 2 Average daily live-weight gain of the high durability $(\bullet)$, high production $(\mathbf{\Delta})$, and New Zealand $(\mathbf{\square})$ strains estimated using the von Bertalanffy growth function.

Table 3 Least-squares means and standard errors (in parenthesis) for the asymptote (A), constant of integration (B) and maturation rate (k) of length, girth and height in the high durability (HD), high production (HP) and New Zealand (NZ) strains

\begin{tabular}{|c|c|c|c|c|}
\hline & \multicolumn{3}{|c|}{ Strain } & \multirow[b]{2}{*}{ Significance } \\
\hline & HP & HD & NZ & \\
\hline \multicolumn{5}{|l|}{ Length } \\
\hline$A(\mathrm{~cm})$ & $120 \cdot 8(0.93)$ & $120 \cdot 5(1 \cdot 03)$ & $117 \cdot 8(0.95)$ & \\
\hline$B(\times 100)$ & $19 \cdot 0(0 \cdot 28)$ & $19 \cdot 1(0 \cdot 32)$ & $19 \cdot 0(0 \cdot 29)$ & \\
\hline$k($ per day $\times 1000)$ & $4.0(0.14)$ & $3 \cdot 8(0 \cdot 15)$ & $3.9(0.14)$ & \\
\hline \multicolumn{5}{|l|}{ Girth } \\
\hline$A(\mathrm{~cm})$ & $205 \cdot 6^{\mathrm{ab}}(2 \cdot 68)$ & $212 \cdot 5^{a}(2 \cdot 98)$ & $201 \cdot 0^{\mathrm{b}}(2 \cdot 74)$ & * \\
\hline$B(\times 100)$ & $25 \cdot 8(0 \cdot 25)$ & $26 \cdot 2(0.28)$ & $26 \cdot 2(0 \cdot 25)$ & \\
\hline$k($ per day $\times 1000)$ & $3.2^{a}(0.09)$ & $2.9^{b}(0 \cdot 10)$ & $3.3^{a}(0.09)$ & ** \\
\hline \multicolumn{5}{|l|}{ Height } \\
\hline$A(\mathrm{~cm})$ & $134 \cdot 9^{a}(0 \cdot 79)$ & $133 \cdot 8^{a}(0 \cdot 88)$ & $128 \cdot 4^{\mathrm{b}}(0 \cdot 81)$ & $\star \star \star ~$ \\
\hline$B(\times 100)$ & $18.7(0.23)$ & $18.6(0.26)$ & $19 \cdot 2(0 \cdot 24)$ & \\
\hline$k($ per day $\times 1000)$ & $4 \cdot 0^{a}(0 \cdot 14)$ & $4 \cdot 1^{a}(0 \cdot 15)$ & $4 \cdot 7^{\mathrm{b}}(0 \cdot 14)$ & $\star *$ \\
\hline
\end{tabular}

${ }_{\text {ab }}$ Means with different superscripts within the same row are significantly different $(P<0.05)$.

Body size

The residuals from predicting actual length, girth and height from the von Bertalanffy growth function all fitted a normal distribution and are summarized in Table 1 for birth, 100 and 600 days of age. The coefficients of variation of the residuals for length, girth and height residuals at birth, 100 days of age and 600 days of age were all less than 0.06 (Table 1). The correlation between the residuals and age was $-0.03,-0.05$, and 0.11 for length, girth and height, respectively; correlations of girth and height residuals with age were significantly $(P<0.05)$ different from zero. The existence of a positive autocorrelation for all residuals of height was rejected. However, the existence of a positive autocorrelation for the residuals of length or girth was neither accepted nor rejected; the Durbin-Watson statistic was 1.9 and 1.6 for length and girth residuals, respectively. Graphical investigation of the relationship between either the length or girth residuals against age revealed no obvious trend. The average mean square prediction error for length, girth and height was $15.3 \mathrm{~cm}^{2}, 12.8 \mathrm{~cm}^{2}$, and $6.9 \mathrm{~cm}^{2}$, respectively. Average $R^{2}$ for length, girth and height across all animals was $0.95,0.99$ and 0.98 , respectively.

Because of the large residuals in estimating birth size with the von Bertalanffy growth function, actual birth dimensions were analysed instead of predicted birth dimensions. A total of 74 animals had measures of body size at birth. No significant difference in birth length existed between the three strains; average birth length per strain varied from 71 $\mathrm{cm}$ to $72 \mathrm{~cm}$. No significant difference in birth girth existed between the three strains; average birth girth per strain varied from $84 \mathrm{~cm}$ to $85 \mathrm{~cm}$. Birth height of the HP $(69.3$ $\mathrm{cm})$ and the $\mathrm{HD}(67.7 \mathrm{~cm})$ strains were significantly $(P<0.05)$ taller than birth height of the NZ strain $(62.7 \mathrm{~cm})$.

The average $A, B$ and $k$ parameters of the von Bertalanffy function for the length, girth and height of the strains are summarized in Table 3. Growth curves for length, girth and height estimated using the von Bertalanffy growth function for the three different strains from birth to 1825 days ( 5 years) of age are shown in Figure 3a, b and c, respectively. 


\section{Growth curves for three strains of cattle}

Figure 3 Profiles of (a) body length, (b) body girth and (c) body height for the high durability ( $\bullet$ ), high production ( $\mathbf{\Delta}$ ), and New Zealand ( $\square$ ) strains estimated using the von Bertalanffy growth function.

(a)

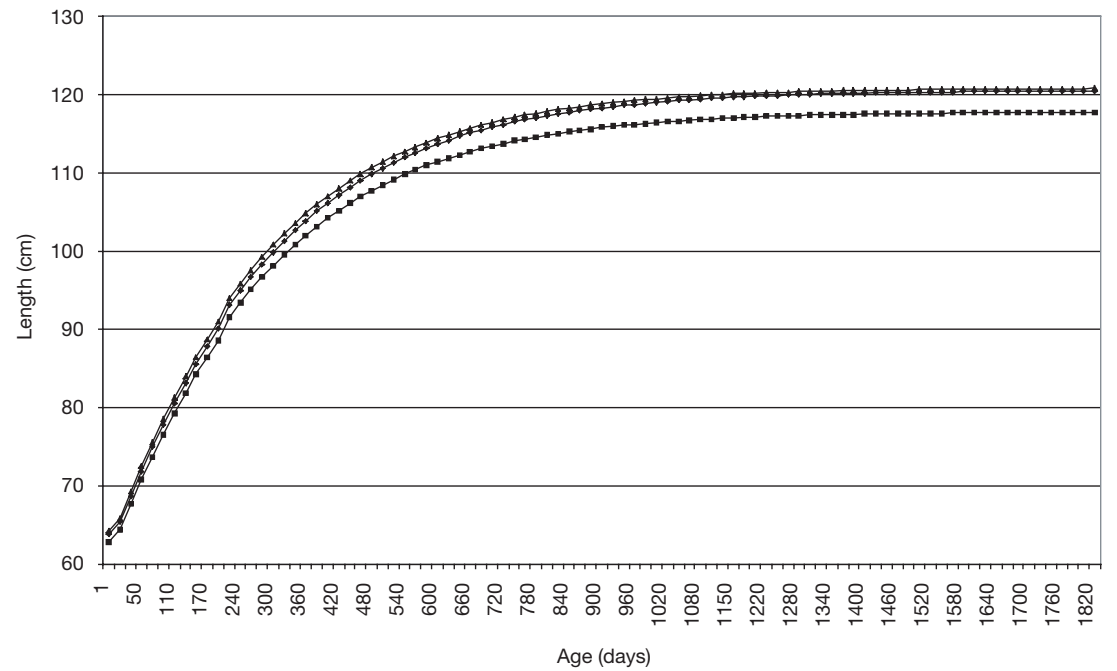

(b)

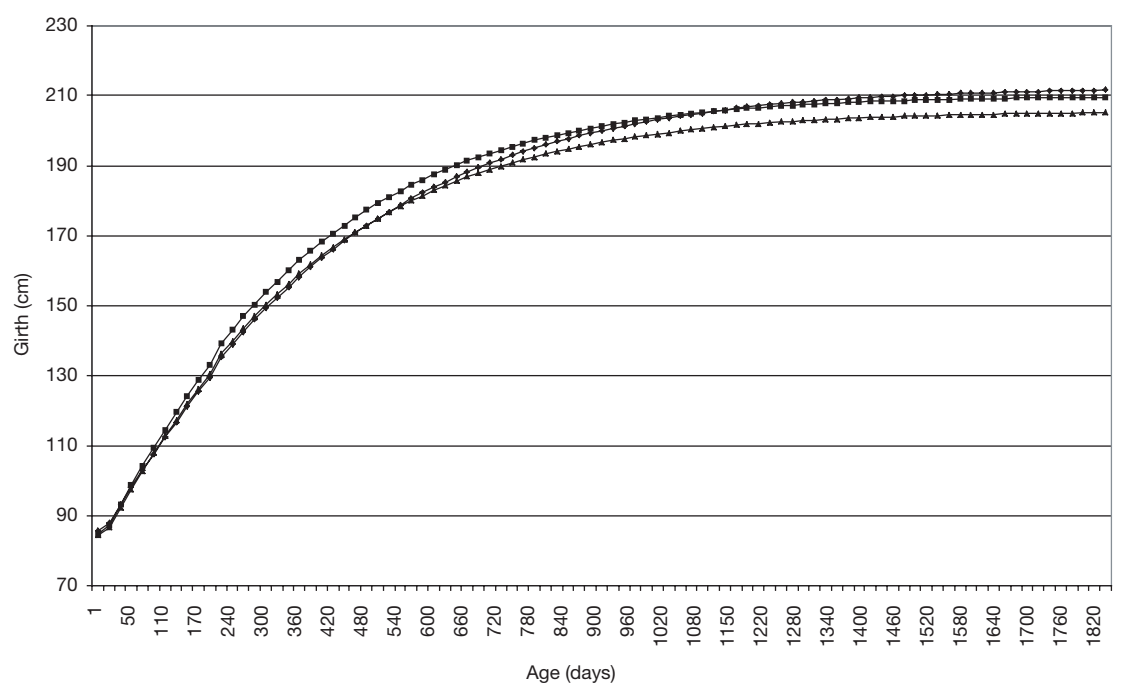

(c)

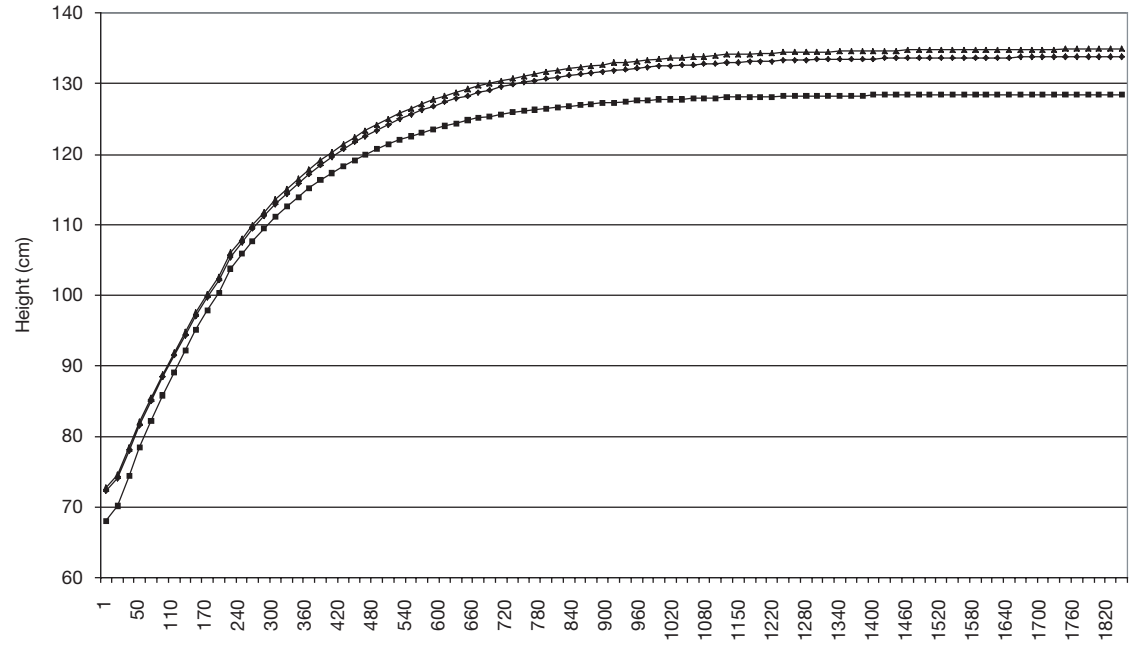




\section{Berry, Horan and Dillon}

Average mature length of the different strains varied from $117.8 \mathrm{~cm}$ to $120.8 \mathrm{~cm}$; no significant difference existed between the three strains (Table 3). No significant difference existed among strains for average daily increase in length at either $100(0.13$ to $0.14 \mathrm{~cm} /$ day $)$ or $600(0.02$ to $0.03 \mathrm{~cm} /$ day $)$ days of age.

Mature girth of the HD strain was significantly greater than mature girth of the NZ strain but not significantly different from mature girth of the HP strain (Table 3). Average daily increase in girth at 100 days of age was significantly $(P<0.05)$ lower for the HD $(0.23 \mathrm{~cm} /$ day $)$ strain compared with the HP $(0.24 \mathrm{~cm} /$ day $)$ and NZ $(0.24 \mathrm{~cm} /$ day $)$ strains. Average daily change in girth at 600 days was significantly $(P<0.05)$ higher for the HD $(0.077 \mathrm{~cm} /$ day $)$ strain compared with the HP $(0.069 \mathrm{~cm} /$ day $)$ and $\mathrm{NZ}$ strain $(0.067 \mathrm{~cm} /$ day $)$.

Mature height was significantly greater for the HP (134.9 $\mathrm{cm})$ and HD $(133.8 \mathrm{~cm})$ strains compared with the NZ (128.4 $\mathrm{cm})$ strain; no significant difference in mature height existed between the HP and HD strain. No significant difference in rate of gain in height existed between the three strains at 100 days of age $(0.15$ to $0.17 \mathrm{~cm} /$ day $)$. Daily height gain at 600 days of age was significantly $(P<0.05)$ higher for the HP and HD strains $(0.026$ to $0.027 \mathrm{~cm} /$ day $)$ compared with the $\mathrm{NZ}(0.021 \mathrm{~cm} /$ day $)$.

\section{Discussion}

The objective of this study was to compare LW and body size of three strains of female dairy cattle of alternative genetic background. Although the size of the data set and the number of sires used in the study were few, there were indications that the HD strain matured more slowly and reached a higher mature weight than either the HP or the NZ strains. The HP and HD strains were significantly taller than the NZ strain with no significant difference in body length between the three strains. Average girth of the HD strain was significantly larger than the NZ strain; average girth of the HP strain was not significantly different from either the HD or the NZ strains. Nevertheless, caution should be expressed when extrapolating these results to the general population.

\section{Live weight}

The existence of a positive autocorrelation agrees with other previous reports using the von Bertalanffy function fitted to LW data (Koenen and Groen, 1996). In agreement with the present study, Brown et al. (1976) also reported a poor fit of the von Bertalanffy function to early periods of LW growth. However, most studies describing bovine LW change have reported superiority of the von Bertalanffy growth function over other growth functions with regard to computational ease and goodness of fit (López de Torre et al., 1992; Vaccaro and Rivero, 1985; Wada et al., 1983). The high mean square prediction error in the present study is expected given that the von Bertalanffy growth function smooths out the random noise which includes gestation and body tissue metabolism during lactation. Bakker and Koops (1978) reported lower residual variation and higher $R^{2}$ values when gestation and lactation were accounted for. However, Bakker and Koops (1978) did not report the effect of such adjustments on the von Bertalanffy growth function parameter estimates. Koenen and Groen (1996) only used heifer data prior to 600 days of age when the effect of gestation is expected to be minimal. In the present study we opted to use all data available and to allow the growth function to account for both gestation and lactation thereby modeling the underlying growth of the animal.

Mean calf birth LW of the HD and HP strains was slightly higher than the mean calf birth LW $(39.5 \mathrm{~kg})$ reported in Holsteins in the United States (Kertz et al., 1997). Average birth LW of the NZ strain (36 kg) was within the average birth LW of two strains of New Zealand Holstein-Friesians selected for high $(41 \mathrm{~kg})$ or low $(35 \mathrm{~kg})$ LW (García-Muñiz et al., 1998).

The HD animals had a $48.4 \mathrm{~kg}$ heavier mature weight than the NZ animals which is similar to the difference in breed effect $(44.4 \mathrm{~kg})$ estimated by Harris and Winkelman (2000) among primiparous cows in New Zealand. The lack of a significant difference in mature LW between the HP and the NZ strains may be due in part to a paucity of data included in the analysis; the difference between the strains approached significance $(P=0.08)$ despite the large standard errors of the estimates for asymptotic LW. The lack of a significant difference in LW between the HP and the NZ strains may also be a function of the lower BCS of the HP animals compared with the NZ animals (Horan et al., 2004). Following the adjustment of all LW records to a common BCS of three the difference between the strains became more diverse. This is expected since the HP strain was significantly taller than the NZ strain.

Live weight of the NZ strain in the present study is higher than the 400 to $450 \mathrm{~kg}$ estimated LW reported by Cue et al. (1996) in New Zealand primiparous cows sired by HolsteinFriesian sires; LW at first calving in the present study was 457 $\mathrm{kg}$ while mature weight was $543 \mathrm{~kg}$. Reasons for differences between the studies may be four-fold: (a) differences in feeding systems across countries; (b) cows measured in the present study were less than $12.5 \%$ Jersey while HolsteinFriesian defined by Cue et al. (1996) was when the sire of the cow was Holstein-Friesian, therefore the cows measured could be up to $50 \%$ of an alternative breed; (c) differences in measuring LW; LW in the present study was measured using calibrated electronic scales while LW measured by Cue et al. (1996) was subjectively assessed by type classifiers to the nearest $50 \mathrm{~kg}$; and (d) the relatively small data set used in the present study which may be subjected to sampling bias.

Average LW at first calving (excluding the weight of the foetus and associated fluids and membranes) reported in the present study for the HP and HD strains was lower than the LW of $559 \mathrm{~kg}$ recorded 1 to 7 days post first calving reported by Hoffman (1997) in his review of seven studies on Holstein animals from the US and Canada.

The constant of integration reported in the present study agrees with previous studies that reported a mean constant of integration in bovines of between 0.50 and 0.68 (Brown et al., 1976; García-Muñiz et al., 1998; Koenen and Groen, 


\section{Growth curves for three strains of cattle}

1996). The lack of a large variation is attributable largely to the non-variable nature of the exponent in the von Bertalanffy growth function. Nevertheless, Koenen and Groen (1996) reported a heritability of 0.31 for the parameter indicating some level of genetic variation.

Differences between strains for maturing rate were significant $(P<0.01)$. This is despite the low heritability $(0.02$; s.e.0.05) reported by Koenen and Groen (1996) for maturing rate in Dutch black and white cows. The rate of maturing reported in the present study was larger than that reported by Koenen and Groen (1996).

The higher mature LW and slower rate of maturing of the HD strain agree with previous reports on Holstein-Friesian (Koenen and Groen, 1996) and beef cows (Brown et al., 1976; López de Torre et al., 1992) which document a negative correlation between asymptotic mature LW and maturation rate; later maturing animals tend to grow to a larger mature LW. This is also illustrated in Figure 2 which shows a lower LW gain in early life in the HD strain compared with the HP strain and also that the HD strain reach their maximum growth rate at a significantly later age. This is expected given the attributes of the von Bertalanffy function; the point of inflection (i.e. the point of maximum growth rate) occurs at 0.296 times the mature weight. Average daily gain in LW, calculated from the reported von Bertalanffy parameter estimates in Dutch black and white dairy heifers (Koenen and Groen, 1996), was $0.73 \mathrm{~kg} /$ day and $0.49 \mathrm{~kg} /$ day at 100 and 600 days of age, respectively. Thus, average daily gain of the HD strain reported in the present study was similar to that calculated from the reported parameters of Koenen and Groen (1996) at the same age.

\section{Body size}

The authors are unaware of any recent study that has used the von Bertalanffy growth function to describe the growth patterns of length, girth and height of Holstein-Friesian females. Nevertheless, the growth function fitted the data very well with $R^{2}$ values larger than when the function was fitted to the LW data; this is mainly due to the smaller effect of gestation and lactation on body size compared with LW. The lack of any strong evidence of positive autocorrelations between the residuals and the relatively low coefficient of variation of the residuals also indicated a good fit of the von Bertalanffy function to the length, girth and height data.

The lack of a significant difference in average length of the three strains suggests a minimal effect of genetic origin on body length. However, mature body length varied from 111 to $137 \mathrm{~cm}$ across all animals indicating some level of variation for body length among animals. Although measured differently, Hoffman (1997) suggested that body length in Holstein heifers should increase by $0.20 \mathrm{~cm} /$ day and $0.07 \mathrm{~cm} /$ day around 100 and 600 days of age, respectively; body length measured by Hoffman (1997) was from the point of the shoulders to the ischium. This is higher than the reported growth rates in body length across all strains in the present study.

The range in mature girth of the three strains $(201.0 \mathrm{~cm}$ to $212.5 \mathrm{~cm}$ ) corroborates previous estimates of girth circumference in Holstein-Friesians (Gallo et al., 2001). The significantly larger girth of the HD strain compared with the NZ strain is a function of differential sire selection criteria among the different strains. Sires used in the HD strain were selected for high milk production simultaneous with high muscularity which may translate into larger heart girths. Sire PTA for chest width and body condition score in the HD strain were respectively 0.86 and 1.36 units higher than sire PTA in the HP strain.

Both the HD and HP strains were significantly taller than the NZ strain. This may be partly attributed to the positive genetic correlations between milk yield and stature/ height (Visscher and Goddard, 1995; Berry et al., 2005). Cows of North American Holstein-Friesian ancestry are selected more intensely for milk production than cows of New Zealand ancestry who were also indirectly selected for optimal fertility simultaneous with high milk solids and lower LW. Nevertheless, mature wither height is lower than the recommended wither height in the US; Hoffman (1997) recommended a wither height of 138 to $141 \mathrm{~cm}$ at first calving. Wither height at first calving across eight Israeli commercial herds was $129 \mathrm{~cm}$ (Markusfeld and Ezra, 1993) which is more in line with the current results; predicted wither height at first calving was $129 \mathrm{~cm}$ and $130 \mathrm{~cm}$ for the HP and HD strains, respectively. Cue et al. (1996) reported a mean score of six for stature across 59623 Holstein-Friesian primiparous cows in herds participating in the Sire Proving Scheme in New Zealand. A score of six for stature in the type classification scheme in New Zealand reflects approximately 125 to $130 \mathrm{~cm}$ in height from the shoulders to the ground which is similar to the mature height reported in the present study.

Hoffman (1997) reported a height growth rate at 100 days of age $(0.20 \mathrm{~cm} /$ day $)$ similar to that reported in the present study. However, growth rate in height reported by Hoffman (1997) at 600 days of age $(0.07 \mathrm{~cm} /$ day $)$ was higher than growth rates reported across all strains in the present study.

\section{Conclusions}

The number of animals and sires used in the study were few and thus the results should be treated with caution when inferences are made to the population as a whole. Given possible genetic variation in LW and body size, the differences observed in the present study may be a reflection more so of the sample population under investigation (i.e. sampling bias among sires) rather than the true genetic differences between strains. However, few recent studies are available on a larger scale which evaluate LW and body size characteristics of alternative strains of dairy cattle, especially under grazing environments. This study indicates significant differences in mature LW and other growth related variables between strains of Holstein-Friesian females. Strain had no significant effect on body length although large phenotypic differences in body length were observed between animals. Significant differences were observed between strains for mature girth circumference. Animals of North American/European origin were significantly taller than animals of predominantly NZ origin. 


\section{Acknowledgements}

The authors would like to acknowledge the help of the farm staff at both Moorepark Research Centre and Curtins Research Farm for caring after the animals and facilitating the collection and recording of the measurements on all animals.

\section{References}

Ahlborn-Breier, G. and Wickham, B. W. 1990. A selection index for production, management and conformation traits. Proceedings of the fourth world congress on genetics applied to livestock production, Edinburgh, vol. 14, pp. 86-89

Bakker, H. and Koops, W. J. 1978. An approach to the comparison of growth curves of Dutch Friesian, British Friesian and Holstein Friesian cows. Current topics in veterinary medicine. Patterns of Growth and Development in Cattle 2: 705-715.

Berry, D. P., Buckley, F., Dillon, P., Evans, R. D. and Veerkamp, R. F. 2005. Genetic relationships among linear type traits, milk yield, body weight, fertility and somatic cell count in primiparous dairy cows. Irish Journal of Agriculture and Food Research In press.

Bertalanffy, L. von. 1957. Quantitative laws in metabolism and growth. Quarterly Reviews of Biology 32: 217-231.

Brody, S. 1945. Bioenergetics and growth. Rheinhold Publishing Corp., NY.

Brown, J. E., Fitzhugh Jr, H. A. and Cartwright, T. C. 1976. A comparison of nonlinear models for describing weight-age relationships in cattle. Journal of Animal Science 42: 810-818.

Cue, R. I., Harris, B. L. and Rendel, J. M. 1996. Genetic parameters for traits other than production in purebred and crossbred New Zealand dairy cattle. Livestock Production Science 45: 123-135.

Durbin, J. and Watson, G. S. 1951. Testing for serial correlations in least squares regression. Biometrika 38: 159-165.

Fallon, R. J. and Harte, F. J. 1987. Calf feeding and management. Beef series no. 1. An Foras Taluntais, Dublin.

Gallo, L., Carnier, P., Cassandro, M., Dal Zotto, R. and Bittante, G. 2001. Test-day genetic analysis of condition score and heart girth in Holstein Friesian cows. Journal of Dairy Science 84: 2321-2326.

García-Muñiz, J. G., Holmes, C. W., Garrick, D. J., LopezVillalobos, N., Wickham, B. W., Wilson, G. F., Brookes, I. M. and Purchas, R. W. 1998. Growth curves and productivity of HolsteinFriesian cows bred for heavy or light mature live weight. Proceedings of the New Zealand Society of Animal Production 58: 68-72.

Grizzle, J. E. and Allen, D. M. 1969. Analyses of growth and dose response curves. Biometrics 25: 357-368.

Groen, A. F. 1989. Economic values in cattle breeding. I. Influence of production circumstances in situations with input limitations. Livestock Production Science 22: 17-30.

Harris, B. L. and Winkelman, A. M. 2000. Influence of North American Holstein genetics on dairy cattle performance in New Zealand. Proceedings of New Zealand Large Herds Conference 6: 122-136.

Heinrichs, A. J., Rogers, G. W. and Cooper, J. B. 1992. Predicting body weight and wither height in Holstein heifers using body measurements. Journal of Dairy Science 75: 3576-3581.

Hoffman, P. C. 1997. Optimum body size of Holstein replacement heifers. Journal of Animal Science 75: 836-845.
Horan, B., Mee, J. F., Rath, M., O'Connor, P. and Dillon, P. 2004. The effect of strain of Holstein-Friesian cow and feeding system on reproductive performance in seasonal-calving milk production systems. Animal Science 79: 453-467.

Kertz, A. F., Reutzel, L. F., Barton, B. A. and Ely, R. L. 1997. Body weight, body condition score, and wither height of prepartum Holstein cows and birth weight and sex of calves by parity: a database and summary. Journal of Dairy Science 80: 525-529.

Koenen, E. P. C. and Groen, A. F. 1996. Genetic analysis of growth patterns of black and white dairy heifers. Journal of Dairy Science 79: 495-501.

Livestock Improvement Corporation. 2003. Dairy statistics 2001/2002. LIC, Hamilton, New Zealand.

López de Torre, G., Candotti, J. J., Reverter, A., Bellido, M. M., Vasco, P., Gárcia, L. J. and Brinks, J. S. 1992. Effects of growth curve parameters on cow efficiency. Journal of Animal Science 70: 2668-2672.

Lowman, B. G., Scott, N. and Somerville, S. 1976. Condition scoring of cattle, revised edition. Bulletin of the East Scotland College of Agriculture, no. 6.

Markusfeld, O. and Ezra, E. 1993. Body measurements, metritis, and postpartum performance of first lactation cows. Journal of Dairy Science 76: 3771-3777.

Pearl, R. and Reed, L. J. 1923. On the mathematical theory of population growth. Metron 3: 6-19.

Perotto, D., Cue, R. I. and Lee, A. J. 1992. Comparison of nonlinear functions for describing the growth curve of three genotypes of dairy cattle. Canadian Journal of Animal Science 72: 773-782.

Richards, F. J. 1959. A flexible growth function for empirical use. Journal of Experimental Botany 10: 290-300.

Sieber, M., Freeman, A. E. and Kelley, D. H. 1988. Relationship between body measurements, body weight, and productivity in Holstein dairy cows. Journal of Dairy Science 71: 3437-3443.

Silvey, M. W. and Haydock, K. P. 1978. A note on live-weight adjustment for pregnancy in cows. Animal Science 27: 113-119.

Statistical Analysis Systems Institute. 2004. User's guide, version 8. 0.0 edition. SAS Institute Inc., Cary, NC.

Vaccaro, R. and Rivero, S. 1985. Growth of Holstein Friesian females in the Venezuelan tropics. Animal Production 40: 279-285.

Van Raden, P. M. and Seykora, A. J. 2004. Net merit as a measure of lifetime profit: 2003 revision. http : //aipl. arsusda. gov/reference/ nmcalc. html Accessed 13/04/04.

Visscher, P. M., Bowman, P. J. and Goddard, M. E. 1994. Breeding objectives for pasture based dairy production systems. Livestock Production Science 40: 123-137.

Visscher, P. M. and Goddard, M. E. 1995. Genetic parameters for milk yield, survival, workability, and type traits for Australian dairy cattle. Journal of Dairy Science 78: 205-220.

Wada, Y., Matsukawa, T. and Sasaki, Y. 1983. Describing weightage relationships in Japanese Black females with non-linear growth models. World conference on animal production. 5. Proceedings of the Japanese Society of Zootechnical Science, Tokyo, pp. 33-34.

Winsor, C. P. 1932. The Gompertz curve as a growth curve. Proceedings of the National Academy of Sciences of the United States of America 18: 1-8.

(Received 30 September 2004 - Accepted 15 November 2004) 